\title{
O USO DAS METODOLOGIAS ATIVAS COMO FACILITADOR DA APRENDIZAGEM MATEMÁTICA
}

DUARTE, Paulo César Xavier ${ }^{1}$

COSTA, Nayla Daniella ${ }^{2}$

\author{
Recebido em: 2020.05 .08
}

Aprovado em: 2020.10.28

ISSUE DOI: $10.3738 / 1982.2278 .3795$

\begin{abstract}
RESUMO: Este trabalho tem como objetivo principal pontuar como o uso de Metodologias Ativas pode facilitar o processo de ensino na aprendizagem Matemática. Trabalhamos especificamente a metodologia PBL - Aprendizagem Baseada em Problemas, para entender como o aluno torna-se centro do processo de aprendizagem, tornando-se assim alternativa para facilitar a aprendizagem dos alunos. Esse estudo se justifica porque a educação contemporânea busca novos rumos, aperfeiçoa-se e evolui constantemente procurando atingir um patamar de especialização que leve a democratização do conhecimento. No aspecto metodológico, sua abordagem é qualitativa, cujo procedimento é uma pesquisa bibliográfica, seguida de observação de campo. E como resultado desta pesquisa destaca-se que o PBL é uma estratégia interessante e eficaz, que os professores deveriam incluir este instrumento de aprendizagem no seu planejamento didático, para suas futuras práticas pedagógicas.Sendo assim, concluímos que com o desenvolvimento da pesquisa, a metodologia PBL permite aos estudantes processar as informações adquiridas por meio da pesquisa, acrescentando novos entendimentos e ampliando assim o conhecimento.
\end{abstract}

Palavras-chave: Metodologias. PBL. Matemática.

\section{THE USE OF ACTIVE METHODOLOGIES AS MATHEMATICS LEARNING FACILITATOR}

SUMMARY: This experience report has as main aim to point out how the use of Active Methodologies can facilitate the teaching process in mathematical learning. The PBL - Problem Based Learning methodology was specifically studied with, to understand how the student becomes the center of the learning process, thus becoming an alternative to facilitate students' learning. This study is justified because the contemporary education look for new directions, gets better and constantly develops seeking to reach a level of specialization that leads to the democratization of knowledge. In the methodological aspect, its approach is qualitative, the procedure is a bibliographic search, followed by field observation. As a result of this research, it is highlighted that the PBL is an interesting and effective strategy that teachers should include this learning tool in their didactic planning, for their future pedagogical practices. Thereby, we conclude that with the research development, the PBL methodology allows students to process information acquired through this research, adding new understandings and so expanding knowledge.

Keywords: Active Methodologies. PBL. Mathematics.

\section{CONSIDERAÇÕES INICIAIS}

Vivemos em um mundo que está em evolução constante devido às inovações tecnológicas e esse processo de constantes modificações provoca também mudanças na visão do homem.

D’Ambrósio (2005) apresenta que logicamente essas transformações atingem a educação, sendo que estas se concentram nos procedimentos, métodos ou técnicas utilizadas. Isto se torna necessário, pois a sociedade contemporânea exige cidadãos cada vez mais eficientes e capacitados para agir e interagir nas diferentes situações do cotidiano que lhe são apresentadas.

\footnotetext{
${ }^{1}$ Pós Doutor em Educação Matemática pela UNIAN, Doutor e Mestre em Educação Matemática pela Unesp de Rio Claro- SP. Professor EBTT do Departamento de Matemática do IFSULDEMINAS-Campus Pouso Alegre

${ }^{2}$ Especialista em Educação Matemática- IFSULDEMINAS- Campus Pouso Alegre.
} 
Porém, a educação por si só se adapta e se transforma acompanhando as mudanças da vida moderna e tem um papel fundamental de formar os indivíduos que atuam nessa sociedade, sendo responsável pelo desenvolvimento criativo do homem. A escola deve propiciar ao aluno novas formas de aprendizado com o uso das tecnologias e precisa estar inserida nesse mundo contemporâneo, mas essa não é uma tarefa das mais fáceis.

Sendo assim, as tendências metodológicas atuais têm como necessidade tornar o aluno "sujeito" ativo, construindo seu próprio conhecimento e aproveitando sua vivência cotidiana no desenvolvimento do aprendizado matemático. Essas tendências tratam o conhecimento matemático de forma viva e contextualizada, se aproximando da realidade do aluno. Como os jovens de hoje já nascem e crescem interagindo com esse mundo, conseguem facilmente se adaptar as novidades.

Entretanto, diante dos novos desafios impostos à sociedade contemporânea, podemos evidenciar problemas educacionais, principalmente os relacionados à matemática, que surgem devido a grande dificuldade dos estudantes fazerem o link dos conceitos com a vida profissional.

Assim, por meio dessas questões levantadas, procuramos apontar como o uso de Metodologias, em especial a Metodologia PBL - Aprendizagem baseada em problemas, podem facilitar o processo de ensino na aprendizagem matemática.

Convém destacar que o objetivo geral deste trabalho é apontar como o uso de metodologias ativas pode facilitar o processo de ensino na aprendizagem matemática. E os objetivos específicos são: apresentar e discutir sobre o PBL, buscando visões de vários autores acerca da utilização do PBL; Observar a aplicação o PBL em sala de aula como metodologia de ensino com os alunos do curso de engenharia de uma universidade e observar e verificar vantagens e desvantagens do PBL na abordagem dos conceitos e solução dos problemas.

Esse estudo se justifica porque a educação contemporânea trilha novos rumos, aperfeiçoase e evolui constantemente buscando atingir um patamar de especialização que leve a democratização do conhecimento. As mudanças constantes por si só é um desafio, sendo necessário entender qual a contribuição da Educação Matemática, na contemporaneidade, como agente transformador de conceitos e como ciência capaz de inter-relacionar as diversas áreas do conhecimento.

Assim, por meio dessas questões levantadas, podemos destacar que este estudo é relevante pois apontar o uso de Metodologias, em especial a Metodologia PBL - Aprendizagem baseada em problemas, pode facilitar o processo de ensino na aprendizagem matemática. 


\section{FUNDAMENTAÇÃO TEÓRICA}

Esse estudo foi desenvolvido por acreditarmos na necessidade de mudança na Educação Matemática. Podemos perceber com os avanços teóricos de aprendizagem e o surgimento de novas tecnologias aplicadas à educação alterações importantes no aprendizado da Matemática e de outras ciências, os profissionais precisam se preparar e capacitar para se adaptar a essa carga de conhecimento.

D'Ambrósio (1986, 1990, 2001), coloca que são necessárias mudanças na Educação Matemática e que avançar neste processo não é tarefa fácil, mas acredita não existir outro caminho. Coloca ainda que a tecnologia aliada a este processo torna-se uma poderosa ferramenta para a construção de conhecimentos e habilidades na Educação Matemática.

Isto nos remete a Perez e Castillo (1999):

quando a proposta educacional é centrada na aprendizagem (auto-aprendizagem e interaprendizagem) e não no ensino, o protagonista do processo se desloca do docente para o educando, e abre-se caminho para que o ato educativo seja entendido como construção de conhecimento, intercâmbio de experiências e criação de novas formas. Esse novo protagonista, por meio do fazer educativo, se apropria da história e da cultura (PEREZ; CASTILLO, 1999).

É evidente que não podemos fugir do impacto tecnológico no âmbito social. Na escola essa tecnologia pode beneficiar no processo sendo utilizadascomo ferramentas na execução de diversas atividades, permitindo ao aluno uma participação mais ativa.

Segundo D'Ambrósio (1986) estamos na "sociedade do conhecimento". Nesse sentido é essencial a escola estimular o conhecimento com a integração de valores da sociedade rumo a uma aprendizagem cada vez mais significativa. $\mathrm{O}$ aprendizado é fundamental para o desenvolvimento do ser humano, ele acontece com a interação social e possibilita o processo de desenvolvimento.

A missão da escola e do educador é auxiliar no momento de incertezas preparando crianças, jovens e adultos para serem instrumentos de mudança. É necessário que o educador entenda que a matemática deve ser útil aos alunos, ajudando-os a compreender a sua realidade. A escola por ser um organismo social transformador deve estar inserida na sociedade em que ela reflete, ela deve preparar o aluno no desenvolvimento de capacidades e habilidades que o integre socialmente e o faça interagir.

A escola deve buscar meios, métodos e técnicas que possibilitem essas ações. É fundamental a qualificação do professor, o aprimoramento e a mudança de visão do ensino da matemática.

Para D'Ambrósio (1986) a Matemática, como ciência, precisa ser estudada dentro de um contexto próprio. Ainda segundo o autor, o programa Etnomatemática: 
tenta acabar com os conhecimentos estabelecidos e identificados no seio de uma população específica no intuito de identificar os processos geradores e formadores dos conceitos produzidos e sua posterior difusão no contexto estabelecido na tentativa de identificar os significados primordiais que motivam os integrantes do mesmo a difundir suas práticas com vistas a atenderem suas necessidades básicas (D’AMBRÓSIO, 1986).

Acredita-se que a metodologia PBL em futuro próximo será cada vez mais utilizada em sala de aula e terá grande importância para a aprendizagem dos conteúdos, possibilitando a aproximação da Matemática com as demais áreas. Resultando na interdisciplinaridade, fazendo com que o aluno se desenvolva de forma integral.

Após estas considerações, pontuamos que essa é uma proposta alternativa ao ensino tradicional, uma maneira interessante de ensinar, uma tarefa difícil, mas necessária, pois a educação precisa se adequar ao mundo contemporâneo por meio de metodologias ativas, como a aprendizagem baseada em problemas. Essa metodologia relaciona a teoria com a prática, trabalhando com problemas reais do cotidiano do aluno, proporcionando uma convivência com problemas possíveis de acontecer, essa maneira enriquece o aprendizado do aluno e o prepara para vida profissional.

\section{METODOLOGIA}

Após o problema de pesquisa definido: Como o uso de metodologias ativas pode facilitar o processo de ensino na aprendizagem matemática? Podemos pontuar que quanto à abordagem, esta pesquisa é qualitativa pois,

este tipo de abordagem trabalha com o universo de significados, motivos, aspirações, crenças, valores e atitudes, o que corresponde a um espaço mais profundo das relações, dos processos e dos fenômenos que não podem ser reduzidos à operacionalização de variáveis (MINAYO, 2001).

Ressaltamos então que a abordagem desta pesquisa é qualitativa seguida de observação em campo. A intenção é entender e aprofundar a análise e observação dos fenômenos, que serão explorados a partir da visão dos participantes em seu ambiente natural de vivência e em relação a um contexto apresentado.

Conforme Fustaré (2008), a pesquisa bibliográfica baseia-se no manuseio de obras literárias, sejam elas impressas ou arquivos digitais (FUSTARÉ, 2008). Portanto, tal abordagem gira em torno de um referencial já publicado, sejam esses livros ou artigos científicos a respeito do assunto. Para Lakatos e Marconi (2001), este tipo de pesquisa propicia o exame de um tema ou assunto, mas que agora assumirá novo enfoque ou abordagem, chegando a novas conclusões (LAKATOS; MARCONI, 2001). 
A Pesquisa bibliográfica é o momento onde foi levantada e revisada a literatura existente para a elaboração de conceitos e definição de marcos teórico.E segundo Sampieri, Collado e Lucio (2013):

o enfoque qualitativo é selecionado quando buscamos compreender a perspectiva dos participantes (indivíduos ou grupos pequenos de pessoas que serão pesquisados) sobre os fenômenos que os rodeiam, aprofundar em suas experiências, pontos de vista, opiniões e significados, isto é, a forma como os participantes percebem subjetivamente sua realidade (SAMPIERI, COLLADO e LUCIO, 2013).

Essa pesquisa está focada em entender e interpretar o comportamento, a compreensão, opinião, experiência e expectativas dos envolvidos na aplicação da metodologia ativa. É exploratória e sua intenção é obter a qualidade do resultado alcançado. O recurso de auxílio a essa abordagem qualitativa é a observação em campo que irá proporcionar observar o comportamento (entender a percepção) dos alunos diante da metodologia utilizada.

E quanto ao procedimento, esta pesquisa é bibliográfica, pois

é feita a partir do levantamento de referencias teóricas já analisadas e publicadas por meios escritos e eletrônicos, como livros, artigos científicos, páginas de web sites. Qualquer trabalho científico inicia-se com uma pesquisa bibliográfica, que permite ao pesquisador conhecer o que já estudou sobre o assunto (FONSECA, 2002).

A pesquisa observada se enquadra em todos esses aspectos. Quanto ao universo da pesquisa, foi desenvolvida em uma universidade particular no município de Pouso Alegre - MG, durante o segundo semestre de 2018 com uma turma de engenharia, na disciplina de Estatística e Probabilidade.

Definida a opção pela metodologia de pesquisa a ser utilizada, destacamos que o foco da pesquisa é a metodologia da Aprendizagem baseada em problemas devida sua relevância em proporcionar aprendizagem por meio de problemas reais, buscando meios e ações que facilitem o ensino e a aprendizagem da disciplina.

\subsection{Coleta de Dados}

Especificamente em relação à coleta de dados, foi realizada por meio de observação em campo, questionário e documentos, após a aplicação do PBL no segundo semestre de 2018. A observação será analisada a fim de obter informações relevantes a respeito das possíveis contribuições do PBL para os estudantes e para as aulas de matemática. Nessa pesquisa iremos nos preocupar em observar o processo de investigação, não somente com o resultado da aplicação.

O ambiente escolhido para a observação e coleta de dados foi a sala de aula de uma turma de engenharia mecânica de uma universidade particular do município de Pouso Alegre - 
MG. O campo escolhido contém as pessoas, eventos, situações e experiências que precisamos para responder à pergunta de pesquisa. A observação da aplicação do PBL foi realizada na disciplina de Estatística e Probabilidade.

\section{ANÁLISE DE DADOS E RESULTADOS}

A Estatística é considerada uma área da Matemática Aplicada que tem por finalidade obter conclusões sobre parâmetros do universo, utilizando para isso a coleta, a organização, a descrição, a análise e a interpretação de dados (ver apêndices 1 e 2 que trazem os slides trabalhados em sala, junto com fórmulas e material de apoio trabalhados). Esses conceitos foram trabalhados e discutidos em sala de aula, e após explicada e aplicada a metodologia PBL (utilizando-se de problema real a ser resolvido), estabeleceu-se a sua relação com o conceito e utilização prática pelo profissional no futuro, de forma a motivar os alunos. A aplicação resultou nas experiências que serão descritas abaixo.

Essas experiências foram realizadas no segundo semestre de 2018 com uma turma de engenharia mecânica de 56 alunos de uma universidade particular do município de Pouso Alegre - MG.

Foram realizados dois experimentos com utilização da metodologia PBL e ambos abrangeram os seguintes conceitos trabalhados na disciplina de Estatística e Probabilidade: coleta, organização e descrição de dados, tabelas, cálculos (média, moda, mediana, amplitude, variância, desvio padrão e coeficiente de correlação, análise e interpretação de dados).

Convém destacar que a intenção do método adotado foi com que os alunos entendessem como realizar uma coleta, organizar dados, descrever, aplicar os cálculos e conceitos estudados e realizar a análise e interpretação dos mesmos no seu dia a dia, utilizando-se de problemas reais. Vejamos.

Experiência 1: Este experimento foi todo realizado em sala de aula e os alunosforam dividios em grupos de 7 integrantes. Foi solicitado a eles que fizessem um levantamento da faixa etária dos alunos da Engenharia Mecânica 2BN matriculados na disciplina Estatística e Probabilidade da faculdade. Foi disponibilizada no quadro uma tabela e conforme cada grupo realizava o levantamento, anotava-se no quadro as idades dos integrantes do grupo (ver quadro 2 construído). 
Quadro 2: Levantamento de Idades da Turma de Engenharia

\begin{tabular}{|c|c|c|c|c|c|c|c|}
\hline GRUPO 1 & 39 & 19 & 28 & 19 & 25 & 20 & 34 \\
\hline GRUPO 2 & 24 & 34 & 27 & 28 & 20 & 29 & 27 \\
\hline GRUPO 3 & 21 & 33 & 33 & 27 & 21 & 31 & 23 \\
\hline GRUPO 4 & 19 & 23 & 26 & 23 & 27 & 22 & 33 \\
\hline GRUPO 5 & 20 & 21 & 21 & 23 & 35 & 23 & 20 \\
\hline GRUPO 6 & 19 & 20 & 20 & 22 & 23 & 26 & 24 \\
\hline GRUPO 7 & 22 & 23 & 25 & 22 & 20 & 23 & 20 \\
\hline
\end{tabular}

Fonte: Elaborada pelos Autores

Após esse levantamento foram realizados os cálculos (determinar para cada conjunto de dados: a média, a moda (tipo), a mediana, a amplitude, a variância o desvio padrão, e o coeficiente de variação) para cada conjunto de dados levantado e após os cálculos cada equipe realizou sua interpretação, comparação e explicação dos resultados desses dados.

Experiência 2: Realizada em sala de aula e a coleta de dados no ambiente detrabalho de um dos integrantes do grupo. Os alunos se dividiram em grupos de 7 integrantes. Foi solicitado que eles fizessem um levantamento de dados de algum problema visualizado por eles na área de estudo da engenharia mecânica no ambiente de trabalho de um dos integrantes do grupo, para aplicar os conceitos trabalhados em sala de aula em um ambiente real do aluno. Foram passadas orientações para cada grupo sobre o problema no contexto do ambiente de trabalho e o levantamento que deveria ser realizado. Os alunos coletaram os dados no campo (orientados pela professora) e construíram uma tabela para representar os dados. Após essa fase realizaram os cálculos para os dados levantados e após os cálculos, a interpretação, comparação e explicação dos resultados do problema trabalhado. Nessa segunda experiência os alunos entregaram como produto final um relatório técnico científico e apresentaram um seminário com resultados do problema levantado.

$\mathrm{Na}$ apresentação final, o professor avaliou o processo da aprendizagem verificando se os conhecimentos conceituais e procedimentais alcançados correspondem a resultados concretos de aprendizagem significativa.

Neste ponto da pesquisa, podemos entender o PBL como um método que aprimora o trabalho do educador, pois ele estimula o acompanhamento do processo de investigação desenvolvido pelos alunos e toma ciência de como eles chegam à solução dos problemas que se propuseram a resolver. 
Pôde ser observado com ambas as experiências que os alunos conseguiram entender melhor o conceito e sua aplicabilidade utilizando os exemplos reais de problemas que ocorrem no seu dia a dia; assim quando aproximamos o conceito da realidade do aluno, ele passa a fazer sentido e faz surgir um interesse maior por parte do aluno. Também se observou a atitude pró ativa dos estudantes para a pesquisa de soluções para o problema proposto.

A atividade desenvolvida possibilitou aos alunos exercitar sua capacidade de trabalhar em equipe, trocar experiências, elaborar um levantamento, analisar, solucionar e interpretar problemas, simular as situações problemas encontradas no dia-a-dia. A solução desenvolvida pelos alunos foi construída por meio da interação com os colegas para a troca de conhecimentos e experiência, com a orientação e supervisão da professora responsável pela disciplina.

Foi possível perceber maior motivação, comprometimento e entusiasmo por parte dos alunos para estudar os conceitos abordados, se comparado às reações observadas em aulas exclusivamente expositivas.

Também convém pontuar que através desta pesquisa, notamos que as principais contribuições do PBL identificadas para os estudantes na disciplina de estatística foram:

- A promoção da aprendizagem centrada no aluno estimulando por meio dos problemas o desenvolvimento de habilidades para solução;

- O comprometimento do aluno na busca do conhecimento e construção do seu pensamento crítico;

- A promoção de uma aprendizagem integrada e contextualizada diante do problema apresentado;

- O incentivo à comunicação em grupo;

- O entendimento e não memorização, agregando valor para vida social e profissional;

Enfim o estímulo aos alunos a tomarem suas próprias decisões, definir suas regras e metas que norteará seus trabalhos em equipe.

E quanto às dificuldades encontradas nas experiências elas giraram em torno da:

- Apresentação: nervosismo, vergonha e postura;

- Interpretação: forma de interpretação do resultado;

- Introdução e contextualização do assunto: forma de pensar no contexto do problema a ser apresentado;

- Escrita: passar para o papel a interpretação dos dados e resultados colhidos no desenvolvimento do trabalho.

Apesar das dificuldades, podemos claramente perceber que esse método compreende o ensino aprendizagem por meio de uma visão complexa, diferenciada e transdisciplinar. Permite aos alunos a convivência com o novo, com a diversidade de opiniões, transformando as 
atividades desenvolvidas na sala de aula em situações ricas e significativas para a produção do conhecimento e da aprendizagem.

Em síntese, esse método permite aos estudantes processar as informações adquiridas por meio da pesquisa, acrescentando novos entendimentos relevantes, ampliando assim o conhecimento. Além de pôr em prática determinadas habilidades sociais e a adquirir outras que são fundamentais ao convívio social.

Isso posto, passamos as considerações finais desta pesquisa.

\section{CONSIDERAÇÕES FINAIS}

O objetivo geral desta pesquisa teve como meta mostrar como o uso das metodologias ativas podem facilitar o processo de ensino na aprendizagem matemática e de forma específica, este trabalho apresentou e discutiu sobre o PBL, trazendo diversas visões acerca da utilização desse método.

Foi observada, analisada, relatada e descrita a aplicação o PBL em sala de aula como metodologia de ensino com os alunos do curso de engenharia de uma universidade. Diante das observações realizadas foram apresentadas as vantagens e desvantagens do método na abordagem dos conceitos e solução dos problemas desse caso específico.

Esse estudo foi desenvolvido por acreditarmos na necessidade de mudança na Educação Matemática. Podemos perceber com os avanços atuais, o surgimento de novas tecnologias voltadas à educação, e nesse sentido estão acontecendo mudanças importantes no aprendizado da Matemática e de diversas ciências e para isso os educadores precisam se preparar e capacitar para se adaptar a essa nova realidade.

Diante da era do conhecimento, da diversidade tecnológica, das constantes transformações dos sistemas econômicos, sociais, políticos, culturais, etc é clara a necessidade de um profissional multifacetado, que se adeque à realidade e as exigências desse mundo. Nesse sentido necessitamos de uma reorientação, buscando estimular os educadores nas pesquisas de métodos inovadores que possibilitem o desenvolvimento de competências necessárias centradas no aluno e na aprendizagem.

Sabemos que o processo de ensino aprendizagem são práticas dinâmicas e que um único método não gera os resultados esperados para o exercício profissional. Por fim, acreditamos no PBL como um método interessante que têm alcançado resultados na aprendizagem e desenvolvimento de habilidades profissionais e que pode ser adaptado às mais diferentes realidades e necessidades. Pontuamos que o PBL é uma estratégia eficaz e que os professores deveriam incluir no seu planejamento didático para as futuras práticas pedagógicas. 


\section{REFERÊNCIAS}

D’AMBROSIO, Ubiratan et. al. Sociedade, cultura, matemática e seuensino. Educação e Pesquisa. São Paulo, v.31, n. 1, p.99-120, 2005. Disponívelem:

<http://www.scielo.br/pdf/ep/v31n1/a08v31n1.pdf>.Acesso em: 22 abr 2018.

D'AMBROSIO, Ubiratan et. al. Ubiratan. Da realidade à ação: Reflexões sobre Educação e Matemática. 2.ed. São Paulo: Summus, 1986.

D’AMBROSIO, Ubiratan et. al. Etnomatemática: Elo entre asTradições aModernidade. Belo Horizonte: Autêntica, 2001.

D'AMBROSIO, Ubiratan et. al. Etnomatemática: Arte ou Técnica de explicar econhecer. São Paulo: Ática, 1990, Série Fundamentos.

FONSECA, J. J. S. Metodologia da pesquisa científica. Fortaleza: UEC,2002.

FURASTÉ, Pedro Augusto. Normas Técnicas para o Trabalho Científico: explicitação das normas da ABNT; 14. ed.; Porto Alegre; 2008.

LAKATOS, Eva Maria. MARCONI, Marina de Andrade. Fundamentos de metodologia científica; 4. ed. rev. e ampl. Atlas. São Paulo, 2001.

MINAYO, M. C. S. (Org.). Pesquisa social: teoria, método e criatividade. Rio de Janeiro: Vozes, 1994. p. 51-66.

PEREZ, F.; CASTILLO, D. P. La mediación pedagógica. Buenos Aires: Ciccus, 1999.

SAMPIERI, Roberto Hernandez; COLLADO, Carlos Fernandez; LUCIO, Pilar Baptista. Metodologia de pesquisa [recurso eletrônico]. 5ed. Porto Alegre: Penso, 2013. 